\title{
Qualitative Pedagogical Findings To Improve Critical Thinking Skills
}

Frank DeSimone, Wagner College, USA

John Buzza, Monmouth University, USA

\begin{abstract}
The motivation for this paper comes from need - the need for our students to learn not only subject matter through traditional methods in a classroom, but foundational learning through experiences obtained directly in the workplace. The terminology used today for this student experience is referred to as experiential learning which comes in two forms, either learning 1) by yourself or 2) through experiential education (learning through programs established by others). You can kindly refer to learning by yourself as "nature's way of learning" as it occurs as a direct participation in the life cycle. However, experiential education can be defined more succinctly as a structured approach, using experiences and the direction of others to create the learning curve.
\end{abstract}

The issue at hand is simple - does participatory (experiential) education create critical thinkers among our students and make them more aware of and able to more easily solve the problem(s) at hand? Our diligence has focused on two distinctly different courses in two different semesters (fall 2011 and spring 2012) in two different business disciplines (business marketing and entrepreneurship) at two distinctly different universities (Wagner College and Monmouth University) with one similar problem - is there a significant benefit to experiential learning over traditional classroom pedagogy?

Our findings are profound in the respect that both the participating subjects (students) and the participating businesses achieved significant benefits when this mode of education was used. Our conclusions in the paper signify that although more research is needed to further determine the significance of the impact of experiential learning, we have come away with a true picture of the educational benefits to the students and the productive benefits to the clients involved. An experiential educator's role is to organize and facilitate direct experiences of phenomenon under the assumption that this will lead to genuine (meaningful and long-lasting) learning. This often also requires preparatory and reflective exercises BOTH inside and outside the classroom.

Keywords: Critical Thinking (CT); National Science Foundation (NSF); Solo Taxonomy

\section{INTRODUCTION}

$\mathrm{n}$ the previous article by DeSimone and Buzza entitled "Experiential Learning: Improving The Efficacy of an Undergraduate Business Degree" (2013), the authors reported their quantitative findings of a research study to measure the improvement in Critical Thinking (CT) Skills by students when two different experiential pedagogies were embedded into two different business courses. In short, the authors of this pedagogical research hypothesized that including an experiential component into marketing and entrepreneurial management business classes by itself, regardless of the type of the selected business type (referred as clients), would improve the critical thinking skills of the participating students. It also was hypothesized that critical thinking skills would improve during the course of only one semester. The study concluded that the hypotheses were correct. Since the overall research included two different instructors in two different institutions of higher education teaching five different courses, it was reasoned that sharing qualitative information regarding the study may also be of value toward the development of business school curricula to enhance critical thinking and creativity. This paper is an analysis of the opinions about the experiences during the studies, which were collected as interviews, independent 
mid-semester reviews, and student course evaluations, as well as some requested formal and informal feedback from the participating clients and their related associates. The participants agree with the opinion of Cook at al. (1996) that one of the main problems regarding teaching critical thinking skills is that there are different conceptualizations of the meaning of CT itself and the institution of a wide variety of methods to accomplish the teaching of these skills. As far as the teaching of CT in business is concerned, Rippen et al. (2002) investigated the use of case study methods to teach critical thinking. Celuch and Salma (1998) identified methods of integrating CT skills exercises into business courses and Catanach, Croll \& Crinaker (2000) studied the use of classroom "hands on" activities in CT. Reid (2010) used on-line courses to improve students' CT skills. Haynes and Bailey (2003) studied the use of detailed questioning in the classroom as a way to promote these skills. Cassidy (2006) studied the effects of peer assessment to improve "employability skills." Paulson (2011) used a reality-based group communication problem to enhance CT in the classroom. In fact, CT is often compared to the scientific method in that it is a systematic and procedural approach to the process of thinking. Snyder and Snyder (2008) and Paulson (2011) believe that illstructured problems should be introduced to improve students' CT skills. While valuing all of the above-mentioned approaches to engage business students in critical thinking, the authors of this paper believe that integrating various experiential components into the syllabi of business classes is essential. Reporting the opinions of the other participants about our above-mentioned previous research can provide further guidance for those who may consider the continued use of this pedagogical approach.

\section{The Original Study Design of the Two Experimental Classes}

One of the concepts for the initial study (DeSimone \& Buzza, 2013) was integrating businesses ("Clients") that require and are interested in marketing support with undergraduate business students in an advanced marketing class. In short, students were given the choice to participate on teams created during the class to negotiate and supply marketing services to the selected businesses over the course of a semester. This alternative was offered instead of a traditional final exam. There were some students that volunteered to participate in the experiential learning component and some students that elected not to participate but take a traditional final exam instead. Therefore, we were able to observe a group of student participants and the non-participating students as a control group.

The other entrepreneurial-related courses used the launch of a new product/service idea to create and develop an entrepreneurial start-up as its experiential component. In short, the students were asked to submit two new product ideas each, which are gradually vetted to the selection of one new product idea to be actually developed during the semester. Once the entrepreneurial new product was established, the students were broken into functional teams that actually launched the product by the end of the semester.

The evolving various new class concepts gave the authors a wide open opportunity to implement structures into the syllabi that could improve critical thinking skills of the participating students.

\section{MATERIAL AND METHODS}

This paper's aim is to share the findings of the qualitative evaluation of the two teaching methods and how using experiential components in different ways influenced student learning of critical thinking. The procedures and methods of the opinion collection used in each of the two studies are described. The narrative of opinions collected for the courses taught at Wagner College are followed by the narrative of opinions collected for the courses taught at Monmouth University.

\section{Courses Taught at Wagner College} (MK 311).

At Wagner College, we had two designated courses: (1) Consumer Behavior (MK 301) and (2) Advertising

\section{Opinion Collection from the Clients}

As it relates to the participating businesses (Clients) in the experimental marketing courses taught at Wagner College, at the end of each semester the instructor sent an email to the client's representative thanking 
him/her for their participation and asking for opinions and suggestions about the entire process of the course. In addition, when possible, there was a final wrap-up meeting between the client representative and the instructor to discuss the experience in further detail. At the end of each semester, after the students made their final presentations to the client(s), any updates received from the client(s) (i.e., an advertisement, promotion, etc.) was recorded by the instructor and shared with the students. All correspondence and documents related to each semester's endeavor were collected and filed.

\section{Opinion Collection from the Instructors}

The authors of this paper communicated with the other faculty members across the college regularly on an informal basis and conducted two formal interviews during and following the courses. During the semesters, the authors maintained a file (a kind of diary) where they kept all their notes and/or comments together with comments from colleagues' and other participating parties. All documents were filed per semester for further referencing.

\section{Opinion Collection from the Students}

Feedback from the students was received through their comments pertaining to the semester-end presentations and/or on independent mid-semester diagnostic reviews performed by a "neutral" instructor from outside of the business department. Additional student comments were received from the-end-of-semester student/teacher evaluation forms and informal student/instructor conversations throughout the semester. All documents were filed per semester for further referencing. Some additional unsolicited correspondence was also received from related parties and filed.

A consent certificate was collected from each participant and commenter allowing the author to use the information as part of a publication without mentioning names.

\section{Courses Taught at Monmouth University}

At Monmouth University, there were two designated courses: (1) Entrepreneurship (BM 451) and (2) Small Business Management (BM 434).

\section{Opinion Collection from the Business Partners and Vendors}

As it relates to the participating businesses and vendors in the entrepreneurial courses taught at Monmouth University, at the end of each semester the students presented their developed business plan to all involved parties in a formal presentation. In addition, when possible, there were ongoing discussions between the instructor and the involved partners to discuss the prospects of the new start-up business in further detail. Since the start-up venture was normally refined during the following Small Business Management classes, any updates and/or refinements were recorded by the instructor and shared with the students. All correspondence and documents related to each semester's endeavor were collected and filed.

\section{Opinion Collection from the Instructors}

The authors of this paper communicated regularly with the other faculty members across the University on both a formal basis, through fund requests, and on an informal ongoing basis to refine the overall offering for implementation. During the semesters, the authors integrated those refinements into the business plan as appropriate. All documents were filed per semester for further referencing.

\section{Opinion Collection from the Students}

Feedback from the students was received through their comments pertaining to the semester-end presentations. Additional student comments were received from the-end-of-semester student/teacher evaluation forms and informal student/instructor conversations throughout the semester. There were also meaningful discussions about the class content and the role of the students when the instructor helped students establish their 
entrepreneurial experience on their resumes. All documents were filed per semester for further referencing. Some additional subsequent unsolicited correspondence was also received from students well after the semester was completed. This correspondence was also saved and recorded.

\section{RESULTS/DISCUSSION}

The opinions concerning these teaching methods will be described and discussed independently for the two institutions and the two course types in three independent categories: 1) Instructors opinion, 2) Business participants' opinion, and 3) the Students opinion. Note that all three categories have or may have different or even contradicting interests and perspectives. The summary of these different perspectives will be presented in the Conclusion of this paper.

\section{Opinions about Courses Taught at Wagner College}

\section{The Instructor's Perspective}

The overall feeling of the instructors is that this form of pedagogy is very effective in the application of the course's domain knowledge. The students learn the domain material better, gain context from the client representative's perspective, and obtain an understanding of the expected "pace" to finalized marketing deliverables by deadline. Some instructors believe that the class time dedicated to the experiential teams results in a reduction of the amount of time allotted to lectures and discussion. However, this time tradeoff is partially offset by the additional time the teams need to spend outside the classroom to prepare the marketing deliverables. All the involved instructors unanimously agree that this type of course demands considerable time from the instructor to continually communicate between the client and the student team. All the involved instructors reported increased activity in helping the teams with their final marketing deliverables because, as they expressed, their reputation is on the line with the client and the students. The instructors also pointed out that they must have spent considerably more time and effort than in a regular class to understand the client's business and sufficiently initiate the students' activities. All agreed, however, that the experiential component is much more effective when the students have the opportunity to voluntarily choose their client team as oppose to be appointed. With this voluntary approach, the student is working on a type of business that $\mathrm{s} / \mathrm{he}$ has some interest in. Instructors also conclude that students within the teams are motivated toward those components of the marketing assignments to which they have better background or abilities, such as the ability to draw or experience in graphic design, etc. Most of the instructors agreed that the scheduling of the student team meetings and establishing communication between the students and the clients are challenging. For example, students have spring breaks, long holiday weekends and times allocated for college sports, while businesses operate on a continual basis. All the instructors involved believe that the final student presentations to the client representatives were a positive learning exercise and the professional feedback and resulting discussions were "eye opening" for the students. While the instructors were convinced that the experiential exercise improved critical thinking skills of the students, the assessment results collected via essay prompt evaluation did not consistently prove to be statistically significant. The students seemed to put more effort into the pre-test essay prompts as opposed to the post-test prompts. This coincides with findings by Celuch and Salma (2002) that students tended to over perform on the pre-test.

The essay prompts were reviewed by a number of uninvolved instructors and an unrelated research organization within Wagner College. Great pains were taken to ensure that the Graduate Assistants (GA's) who scored the essays were objective and that the NSF Solo Taxonomy's scoring rubrics were used in a reliable and valid way (Biggs \& Collis, 1982; Chan, 2002; Hattie \& Purdie, 1998). However, some instructors believed the GAs' training in the scoring process may have been insufficient to understand the nuances of scoring critical thinking in an open essay. In future studies, the authors would suggest that professionals skilled in assessing CT essays should be used to score the essays. It is also the opinion of the involved instructors that the students do not take all 20 minutes provided to respond to their essay prompts. It is more evident when the post-semester essay prompts were given. Some instructors argued that because the prompts were anonymous and did not affect the students' grade, the students had limited motivation to apply their maximum CT skills on the post-test. 
Clients' Perspective

Initially, all of the Clients loved the concept when they were first recruited and decided to participate. As the research matured in each new semester, it was easier to obtain new and diverse businesses to participate in the program. After all, the Clients were the ones who received the benefits of free labor from a team of marketing undergraduate students. They were generally receiving marketing deliverables (as most clients do not have the inhouse skills to produce) and they obtained the consultation of an experienced marketing business instructor. In addition, many of the Clients responded that they could take advantage of the available Wagner College infrastructure, using services like the library, print shop, IT department, graphic arts programs, and applications, as well as the provided office and classroom space. Most of the interviewed Client's representatives stated they took pleasure in sharing their business experiences with the students and instructors. The general opinion of the Clients was that they benefitted most from students' creative ideas for their businesses (often referred to by the clients as a unique perspective) as well as the students' enthusiasm and a willingness to work. It also became evident from the interviews that the student teams seemed to fall short of Client expectations when it came to practical application and execution of the "scope of work". This coincides with the current literature that there is a considerable skill gap in CT skills between current undergraduates and the expectation of the workplace (Andrews \& Higson, 2008; Casner-Lotto, Rosenblum, \& Wright, 2009; Cotton, 2001). In many ways, this observation alone justifies the need for this type of pedagogical approach. It was also found that considerable time must be initially invested by the client representative to orient the students to their business issues and their marketing challenges before constructive work can begin on the agreed "scope of work". Furthermore, many of the successful marketing initiatives (i.e., blogging or email marketing campaigns) need to be continued after implementation to maximize the return on investment. In many cases, this has been resolved through ongoing internships. In some cases, this continuation is not a smooth transition. In the opinion of most Clients, the student groups should be continued beyond a single semester, as is possible in the Monmouth University program. This is supported also by CT research by HernandezMarch et al. (2009).

Specific Comments by Clients include:

- I I I Inink this idea opens up the options for a variety of projects such as social media, partnerships with nonprofits, individual/corporate sponsorships, and event planning.

- $\quad$ From the very first meeting, these students have had creative and innovative ideas to reach out to students and administrators.

- $\quad$ Students tend to be creative, come to the table without biases, and are eager to work.

- $\quad$ Each team provided strategies to develop additional programs and events to bolster gate admissions and organizational revenue.

- WOW! WOW! WOW! The instructor just shared the video [that the student team produced] with me. It truly brought tears to my eyes. I look forward to sharing the video with our upcoming Board of Trustees meeting next week.

- $\quad$ Thank you and I would like to participate again next semester. Should I send you one or two project descriptions for your review?

\section{Students' Perspective}

The students overwhelmingly liked the option of participating in an experiential learning exercise. Many of them who did not participate said that they did not participate due only to time or travel constraints. For those who did participate, most believed they gained an invaluable experience, as evidenced by the fact that many of the participating students use this experience on their resume in the same way as an internship might be used. On rare occasions, there were some comments from those who did not participate that they felt a little "left out" during class discussion regarding one of the Client businesses, but the large majority believed the entire class was better because of the experiential component. On the other hand, travel and logistics did present some challenges. Many of the students did not want to travel off campus or meet with their groups outside of regularly scheduled class hours. Many also stated that it was a considerable amount of work in addition to the typical course syllabi. 

component:

Below are some student comments that reflect their sentiment about the syllabi, including the experiential

- $\quad$ This is a good option since some students enjoy out-of-school learning rather than studying for finals.

- $\quad$ This is a great option. However, due to time constraints, it is not possible for many students to take advantage of it.

- This offers hands-on work and real experience, and the two choices [volunteer decision for participating or not participating] make the whole class happy.

- $\quad I$ was able to get a feel for the marketing field in the experiential group.

- Experiential teams were "really" helpful.

Opinion of Other Participants

Other specific participants included the Graduate Assistants who aided the authors with the quantitative research, client participants that were not specifically the client representative, and other professors who provided advice during the research process. Their feedback during the course of the research process helped to formulate the perspectives shared by the authors of this paper.

\section{Opinions about Courses Taught at Monmouth University}

The Instructor's Perspective

While the Monmouth Entrepreneurial Studies Program is popular with students (see below), the instructor found that the classes are not particularly scalable to other instructors and a program expansion in its current form. Instructors for this type of program need a special commitment and relevant entrepreneurial experience. The instructor's workload is considerably more than a class without the entrepreneurial component. A specific communication system needs to be established (it is accomplished largely by computer at Monmouth), which the Director of the Program believes requires constant monitoring and feedback from the instructor. In the case of the Monmouth University entrepreneurial program, there is real money on the line. Therefore, the students get a taste of true business risk. While the students benefit from this exposure because it is a difficult concept to teach in the classroom, the instructor needs to be on top of each project. As stated above in the Wagner College experiential component, continuity of service has been a problem with some of the Clients. In the Monmouth program, this continuity problem has been partially addressed because the Entrepreneurial Studies class develops the start-up company and the small business administration class is available to continue the progress of the start-up beyond the initial semester. Because of the functional team approach, there must be ground rules set at the beginning of each class. The instructor lets the students know there will be additional time spent outside of class (generally 15 hours per week) and that absences will not be tolerated (he generally allows one absence per semester). In exchange, the student will receive "real life" business experience and an entry on their resume that could be more valuable than any internship. The classes also result in a developed business concept, business plan, and launch plan that can easily have value to the students of Monmouth or an outside entity for purchase from the University.

\section{Opinion of Different Partners Involved in the Activities of the Entrepreneurial Experiential Component}

Contrary to the experiential program at Wagner College, the partners involved in this program are often treated strictly as vendors. While the "clients" in the Wagner College program are asked to participate in a sort of three way education of the students, the participants in the entrepreneurial program at Monmouth University are primarily business partners. The instructor interviews the potential partners to orient them to the program, but partners are selected based on the typical "due diligence" of a vendor selection. The instructor, particularly in the entrepreneurship course, lays out the ground rules to the potential business partners and makes it clear there is some "mentoring" that is expected when the opportunity presents itself.

Again, contrary to the Wagner College program, the business partner has grading responsibility. The experiential component is graded based on the instructors observations, the functional team leader's peer evaluation, and the evaluation of the business partners involved with that functional group. 
Students' Perspective

The courses for the Entrepreneurial Studies Center are highly popular and generally receive excellent reviews from the students. Some comments in the ratemyprofessor.com website about the entrepreneurial class include:

- $\quad$ He is one of the best Prof. at MU. He is very clear about the class. 1st day of class he tells that he requires you to put effort. It is more like a business environment then a class. If you are taking 18 do not take this class because, there is lot of work for this class.

- $\quad$ Buzza is the best professor without a doubt. His class is absolutely amazing and the coolest people ever take his class, so if you're one of them, take it!!

In an effort to complete the entrepreneurial project within the semester, deadlines are common. The students come to understand the importance of deadlines as they will be accustomed to in the business world.

However, the courses are not for everyone. It is more work than a normal class for the student. There are peer evaluations, so students cannot easily "hide" from their responsibilities inside or outside class. Furthermore, there needs to be "buy in" from the students to optimize the value of the classes. Obviously, not everyone's idea can be selected. The selection process is fairly structured and the entrepreneur product is democratically chosen, but there is always a chance that some members in the class are not enthused by the selected project. The instructor's credibility is essential to the fairness of the selection process and to achieve this "buy in" from the students.

As a tangible benefit of the program, the students often come to the instructor for letters of recommendation and/or help with the wording used for their entrepreneurial experiential component on their resumes. It is apparent that students see the benefit of the program for career planning purposes. On the other hand, there is a time component that is difficult to manage. For example, in the recent Hurricane Sandy storm in New Jersey, the teams lost momentum and had to scale back expectations for the semester. On balance, however, most students that participated cherished the learning experience.

\section{GENERAL CONCLUSION}

This paper is an analysis of the reports of subjective findings regarding the experiences of the instructors, students, clients and other related participants while conducting quantitative research in the two programs mentioned above.

In the Wagner marketing experiential exercise, it was a rewarding experience for Instructors, Clients and Students. The instructors and students were exposed to current business practices in marketing and the clients and their representatives became acquainted with a fresh academic approach to their business and to the perspective, creativity and energy of the student teams. Students can receive letters of recommendation from the clients and their representatives and lasting contacts in their local business environment. In a time where discussion of the "skill gap" is prevalent in business media, this pedagogical form fulfills the needs of both employers and potential employees.

In the Monmouth entrepreneurial experiential exercise, the Instructor becomes part of the community, raises money for the University, and creates a product or service idea that lasts beyond the semester. It is a rewarding experience for all concerned. The students obtain real exposure to the risks and rewards associated with the entrepreneurial exercise. The students also see how their functional skills (i.e., finance, accounting, law, etc.) fit into the small business environment. In a time where the country is encouraging entrepreneurship among younger people, this pedagogical form fulfills this goal.

\section{ACKNOWLEDGEMENT}

The authors of this paper express their appreciation to Dr. Z Fulop for his kind advice and guidance in this article, Dr. M. LoRe for advice and editing the paper, and to D. Schaub for guidance and organization of the literature research and references. 


\section{AUTHOR INFORMATION}

Frank DeSimone is currently Assistant Professor of Business Administration and Director of External Programs at Wagner College in Staten Island, New York. He holds a Masters of Business Administration from New York University and is currently working towards his Dissertation for his Ph.D. from the International School of Management headquartered in Paris, France. Contact: Department of Business Administration, Wagner College, One Campus Road, Staten Island, NY 10301. E-mail: frank.desimone@ wagner.edu (Corresponding author)

John S. Buzza is currently a Specialist Professor at Monmouth University and the Director of the Monmouth University Center for Entrepreneurship. Monmouth University is located in Long Branch, New Jersey. In 2010, the Entrepreneurship course taught by John Buzza received the "Most Innovative Entrepreneur Course Award" in the Country by the United States Association for Small Business and Entrepreneurship (USASBE). E-mail: johnsbuzza@att.net

\section{REFERENCES}

1. Andrews, J., \& Higson, H. (2008). Graduate employability, "soft skills" versus "hard" business knowledge: A European study. Higher Education in Europe, 33(4), 411-422.

2. Biggs, J. B., \& Collis, K. F. (1982). Evaluating the quality of learning: The SOLO taxonomy (Structure of the observed learning outcome). New York: Academic Press.

3. Casner-Lotto, J., Rosenblum, E., \& Wright, M. (2009). The ill-prepared US workforce: Exploring the challenges of employer-provided workforce readiness training. The Conference Board.

4. Cassidy, S. (2006). Developing employability skills: Peer assessment in higher education. Education + Training, 48(7), 508-517. doi: 10.1108/00400910610705890.

5. Catanach, J., Croll, D. B., \& Grinaker, R. L. (2000). Teaching intermediate financial accounting using a business activity model. Issues in Accounting Education, 15(4), 583-603.

6. Celuch, K., \& Slama, M. (1998). Critical thinking as an integrative theme for teaching lifelong learning skills in marketing. Marketing Education Review, 8(3), 1-12.

7. Celuch, K., \& Slama, M. (2002). Promoting critical thinking and life-long learning: An experiment with the theory of planned behavior. Marketing Education Review, 12(2), 13-22.

8. Chan, C. C. T. (2002). Applying the structure of the Observed Learning Outcomes (SOLO) taxonomy on student's learning outcomes: An empirical study. Assessment \& Evaluation in Higher Education, 27(6), 511-527.

9. Cook, P., Johnson, R., Moore, P., Myers, P., Pauly, S., Pendarvis, F., ... South Carolina Higher Education Assessment Network, R. H. (1996). Critical thinking assessment: Measuring a moving target. Report \& recommendations of the South Carolina Higher Education Assessment Network Critical Thinking Task Force. Retrieved from http://search.ebscohost.com/login.aspx?direct=true\&db=eric\&AN=ED413808\&site=ehost-live

10. Cotton, K. (2001). Classroom questioning. School Improvement Research Series. Retrieved from http://rsd.schoolwires.com/145410515152938173/lib/145410515152938173/Classroom_Questioning by_C otton.pdf

11. DeSimone, F., \& Buzza, J. (2013). Experiential learning: Improving the efficacy of an undergraduate business degree. American Journal of Business Education, 6(1), 7-24.

12. Hattie, J., \& Purdie, N. (1998). The SOLO model: Addressing fundamental measurement issues. Teaching and learning in higher education, 145-176.

13. Haynes, T., \& Bailey, G. (2003). Are you and your basic business students asking the right questions? Business Education Forum, 57(3), 33-37.

14. Hernandez-March, J., del Peso, M. M., \& Leguey, S. (2009). Graduates'skills and higher education: The employers' perspective. Tertiary Education and Management, 15(1), 1-16.

15. Paulson, E. (2011). Group communication and critical thinking competence development using a realitybased project. Business Communication Quarterly, 74(4), 399-411.

16. Reid, J. R. (2010). A quantitative assessment of an application of Halpern's teaching for critical thinking in a business class. ProQuest LLC. Retrieved from http://gateway.proquest.com/openurl?url_ver=Z39.882004\&rft_val_fmt=info:ofi/fmt:kev:mtx:dissertation\&res_dat=xri:pqdiss\&rft_dat=xri:pqdiss:3404869 
17. Rippin, A., Booth, C., Bowie, S., \& Jordan, J. (2002). A complex case: Using the case study method to explore uncertainty and ambiguity in undergraduate business education. Teaching in Higher Education, 7(4), 429-41.

18. Snyder, L. G., \& Snyder, M. J. (2008). Teaching critical thinking and problem solving skills. Delta Pi Epsilon Journal, 50(2), 90-99. 
NOTES 